\title{
A Calcified Hepatic Hydatid Cyst
}

VISHAL SHARMA, ${ }^{1}$ SOURABH AGGARWAL, ${ }^{1}$ ALKA SHARMA ${ }^{1}$

A 55 year old female was evaluated for chronic cough. The chest X-ray done during evaluation revealed a well- defined homogenous lesion with peripheral calcification below the right diaphragm (Figure 1). The findings were confirmed on CT abdomen. The ELISA for Echincoccosis was positive. Computed tomography confirmed the finding of a cystic lesion with calcified wall in the right lobe of liver. The patient refused surgery. She was administered oral albendazole therapy. At three months follow-up the cyst size remained unchanged. Hydatid disease, caused by larvae of
Echinococcus granulosus, may remain entirely asymptomatic. Hepatic cysts, the commonest site, may occasionally be seen on plain roentgenogram on account of calcification. PAIR (percutaneous puncture of the cyst under sonographic guidance, aspiration of substantial amount of the cyst contents, injection of proctoscolicidal agent and reaspiration) is the usual therapy; however it is not possible in lesions with calcified walls. ${ }^{1}$ When surgery is contraindicated or refused, medical treatment with albendazole is recommended.
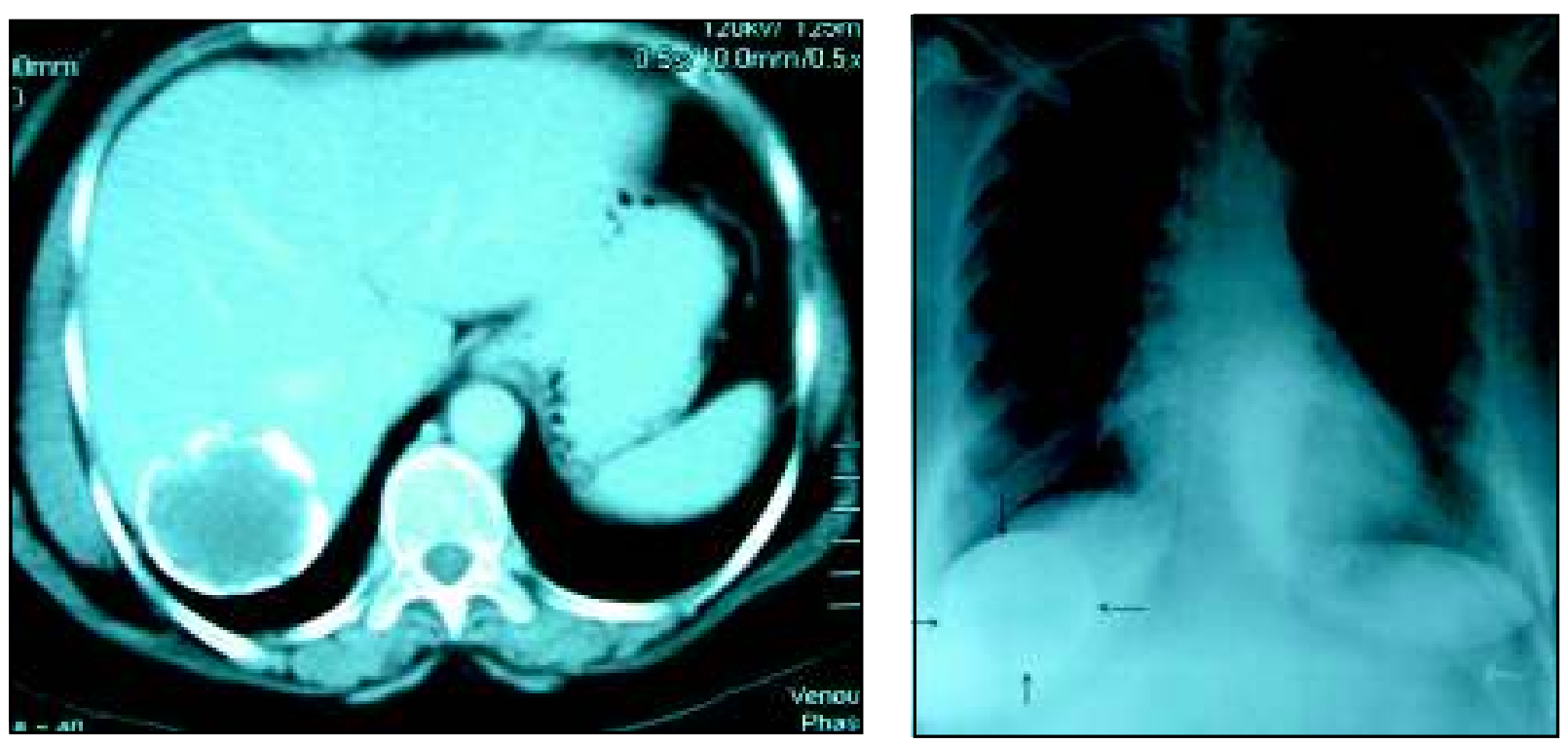

\section{Conflict of Interest : None}

\section{References}

1. Filippou D, Tselepis D, Filippou G, Papadopoulos V. Advances in liver echinococcosis: diagnosis and treatment. Clin Gastroenterol Hepatol 2007; 5: 152-9 .

1. Department of Medicine, University College of Medical Sciences (University of Delhi), Delhi, India

Correspondence : Dr. Vishal Sharma, Department of Medicine University College of Medical Sciences (University of Delhi), Delhi, India e mail:docvishalsharma@gmail.com 